\title{
DETERMINING THE BALANCE CONFIGURATION, IN CASE OF THE OSCILLATING MOVEMENT OF THE MAIN SPINDLE AT CNC LATHE
}

\author{
Daniel Popescu ${ }^{*}$ 四
}

${ }^{* 1}$ Faculty of Mechanics, University of Craiova, Romania

DOI: https://doi.org/10.29121/ijetmr.v7.i6.2020.692

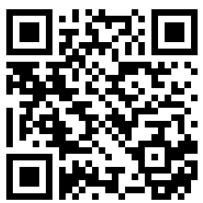

Article Citation: Daniel Popescu. (2020). DETERMINING THE BALANCE CONFIGURATION, IN CASE OF THE OSCILLATING MOVEMENT OF THE MAIN SPINDLE AT CNC LATHE. International Journal of Engineering Technologies and Management Research, 7(6), 41-46.

https://doi.org/10.29121/ijetmr.v7 i6.2020.692

Published Date: 10 June 2020

Keywords:

Oscillating Movement

Main Spindle

CNC Lathe

Balance Configuration

\section{ABSTRACT}

In the paper we present a mathematical model through which are determined the balance conditions, needed for the stability analysis of the oscillating movement of the main spindle at CNC lathe. We take into account Hamilton's variation principle, the axiom of impulse derivative and the axiom of kinetic moment derivative. We present the general movement equations that generate the oscillations based on the calculus hypotheses, performing the introduction of the external solicitations. Establishment of the balance configuration is done by imposing the conditions that the system of forces that act upon the ensemble spindle - bearings - tool causes a deformation of the spindle, without producing spindle vibration. We obtain the new differential equations of the movement, in which the forces and moments are determined from the static case, based on which we can determine the integration constants in the characteristic points of the main spindle.

\section{INTRODUCTION}

Turning plays a special role among cutting technological processes due to its high dynamic instability characteristic of the process. The size of the cutting forces is determined by the material to be processed, the parameters of the cutting regime, the cooling system, the tool material, etc. In what concerns the vibration level at turning, this is higher both for vibrations and auto vibrations, having a negative influence on the results of processing and limiting the productivity. Research results have shown that due of the contact between tool and piece, the amplitude of vibrations in case of inconvenient processing conditions, at few seconds after the start, reaches already the limit values admissible for forced vibrations due to tool instability. The peak values of the dynamic forces that appear under these circumstances produce an increased wear of lathe tools and the deformation of piece turned surface.

\section{THE MATHEMATICAL MODEL FOR ESTABLISHING THE MOVEMENT EQUATIONS OF THE MAIN SPINDLE}

We take into account the following:

- On the external surface of the spindle there are no forces or distributed superficial couples. 
Determining the Balance Configuration, In Case of The Oscillating Movement of The Main Spindle at CNC Lathe

- During rotation there aren't any supplemental supports or other types of links that assume appearance of shocks.

- The initial state of the spindle is considered to be not tensioned (the tensions that occur are in the elastic domain only).

- A plane section normal on the axis of the spindle before deformation remains plane, without keeping the perpendicularity.

The mathematical model takes into account the known principles (Hamilton's variational principle). Based on this we compute the inertial terms and the resultant force and moment of the tensions in section [1].

The movement equation under reduced matrix form is:

$[\mathrm{E}]\{\ddot{\mathrm{q}}\}+[\mathrm{G}]\{\dot{\mathrm{q}}\}+[\mathrm{L}]\{\mathrm{q}\}+[\mathrm{V}]\{\mathrm{q}\}_{, 1}=\{\mathrm{H}\}$

Where:

$[\mathrm{E}]=\left[\begin{array}{cccccc}\rho \mathrm{A} & 0 & 0 & 0 & 0 & 0 \\ 0 & \rho \mathrm{A} & 0 & 0 & 0 & 0 \\ 0 & 0 & \rho \mathrm{A} & 0 & 0 & 0 \\ 0 & 0 & 0 & \rho \mathrm{I}_{1} & 0 & 0 \\ 0 & 0 & \rho \mathrm{A} & 0 & \rho \mathrm{I}_{2} & 0 \\ 0 & -\rho \mathrm{A} & 0 & 0 & \rho \mathrm{I}_{3}\end{array}\right]$
$[\mathrm{G}]=\left[\begin{array}{ccccccc}0 & 0 & 0 & 0 & 0 & 0 \\ 0 & 0 & -2 \rho \mathrm{A} \Omega & 0 & 0 & 0 \\ 0 & 2 \rho \mathrm{A} \Omega & 0 & 0 & 0 & 0 \\ 0 & 0 & 0 & 0 & 0 & 0 \\ 0 & 2 \rho \mathrm{A} \Omega & 0 & 0 & 0 & 0 \\ 0 & 0 & 2 \rho \mathrm{A} \Omega & 0 & 0 & 0\end{array}\right]$

$[\mathrm{L}]=\left[\begin{array}{cccccc}0 & 0 & 0 & 0 & 0 & 0 \\ 0 & -2 \rho \mathrm{A} \Omega^{2} & -\rho \mathrm{A} \dot{\Omega} & 0 & 0 & \frac{\mathrm{EA}}{2(1+\mathrm{v})} \\ 0 & \rho \mathrm{A} \dot{\Omega} & -\rho \mathrm{A} \Omega^{2} & 0 & -\frac{\mathrm{EA}}{2(1+\mathrm{v})} & 0 \\ 0 & 0 & 0 & -\rho \mathrm{I}_{1} \Omega^{2} & 0 & 0 \\ 0 & \rho \mathrm{A} \dot{\Omega} & -\rho \mathrm{A} \Omega^{2} & 0 & 0 & 0 \\ 0 & \rho \mathrm{A} \Omega^{2} & \rho \mathrm{A} \dot{\Omega} & 0 & 0 & 0\end{array}\right]$

$\{\mathrm{q}\}=\left\{\mathrm{u}_{1} \mathrm{u}_{2} \mathrm{u}_{3} \theta_{1,1} \theta_{2,1} \theta_{3,1}\right\}^{\mathrm{T}}$

$\{\mathrm{H}\}=\left\{\begin{array}{llllll}\mathrm{p}_{1} & \mathrm{p}_{2} & \mathrm{p}_{3} & \mathrm{~m}_{1,1} & \mathrm{~m}_{2,1}+\mathrm{p}_{3} & \mathrm{~m}_{3,1}-\mathrm{p}_{2}\end{array}\right\}^{\mathrm{T}}$

$[\mathrm{V}]=\left[\begin{array}{cccccc}-\frac{\mathrm{EA}(1-\mathrm{v})}{(1+\mathrm{v})(1-2 \mathrm{v})} & 0 & 0 & 0 & 0 & 0 \\ 0 & -\frac{\mathrm{EA}}{2(1+\mathrm{v})} & 0 & 0 & 0 & 0 \\ 0 & 0 & -\frac{\mathrm{EA}}{2(1+\mathrm{v})} & 0 & 0 & 0 \\ 0 & 0 & 0 & -\frac{\mathrm{E}}{2(1+v)} \mathrm{I}_{1} & 0 & 0 \\ 0 & 0 & 0 & 0 & -\frac{\mathrm{E}(1-\mathrm{v})}{(1+v)(1-2 v)} \mathrm{I}_{2} & 0 \\ 0 & 0 & 0 & 0 & 0 & -\frac{\mathrm{E}(1-\mathrm{v})}{(1+\mathrm{v})(1-2 \mathrm{v})} \mathrm{I}_{3}\end{array}\right]$ 
We ignore the effect of transversal contraction $(v=0)$, the torsion vibration is null $\left(\theta_{1}=0\right)$, and Bernoulli's law applies [2]:

$$
\theta_{2}=-\mathrm{u}_{3,1} ; \theta_{3}=\mathrm{u}_{2,1}
$$

The accepted notations are the following:

$\rho, A, E, v$ - geometric and mass characteristics of the spindle material

$\Omega$ - angular rotation speed of main spindle

$\mathrm{u}_{1}, \mathrm{u}_{2}, \mathrm{u}_{3}$ - linear displacements of the current point of the section along the coordinate axes

$\theta_{1}, \theta_{2}, \theta_{3}$ - angular displacements of the current point of the section along the coordinate axes

$\mathrm{p}_{1}, \mathrm{p}_{2}, \mathrm{p}_{3}$ - linearly distributed charges along the axes

$\mathrm{m}_{1}, \mathrm{~m}_{2}, \mathrm{~m}_{3}-$ linearly distributed masses along the axes

For a spindle model corresponding to figure 1, the input of external forces $F_{1,1}, F_{2,1}, F_{3,1}$ and couples $M_{2,1}, M_{3,1}$ represents the action of the bearing (i) upon the main spindle (figure 2).

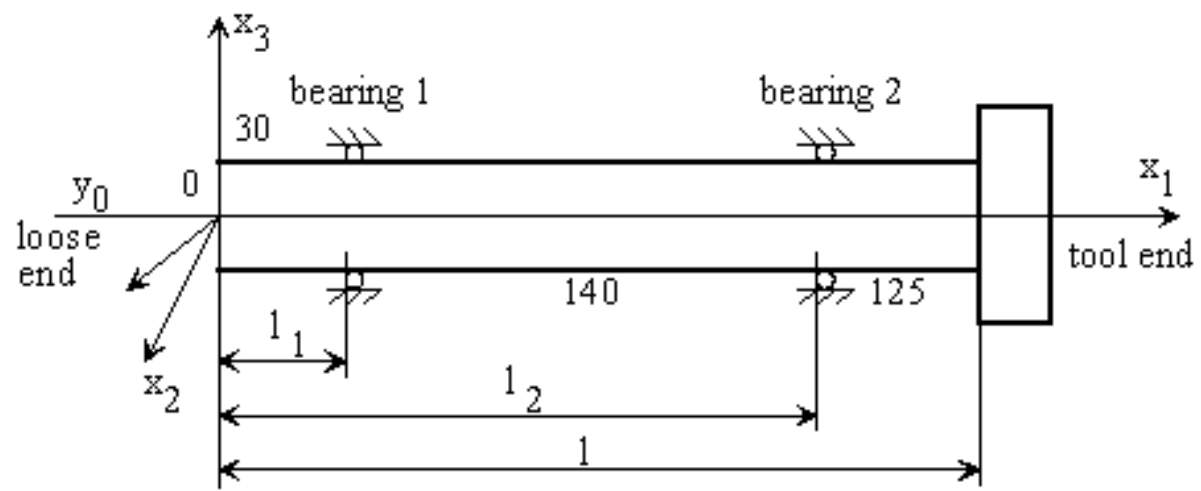

Figure 1: Real model of the spindle

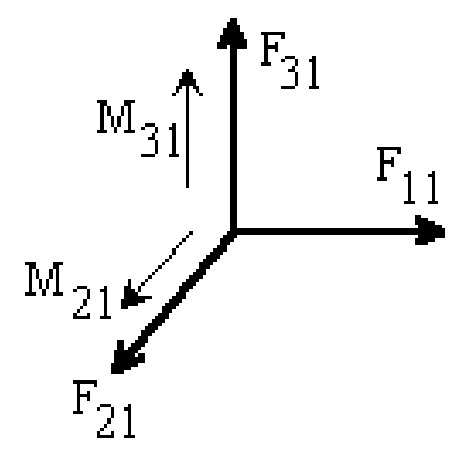

Figure 2: Action of bearing

The distributed forces and moments are given by:

$$
\begin{aligned}
& \{p\}^{(i)}=\left\{\begin{array}{l}
F_{1 i} \\
F_{2 i} \\
F_{3 i}
\end{array}\right\} \delta\left(x_{1}-1_{i}\right) \\
& \{m\}^{(i)}=\left\{\begin{array}{c}
0 \\
M_{2 i} \\
M_{3 i}
\end{array}\right\} \delta\left(x_{1}-1_{i}\right) ;
\end{aligned}
$$


Determining the Balance Configuration, In Case of The Oscillating Movement of The Main Spindle at CNC Lathe

Where $\delta$ - Dirac distribution [3].

The damping introduced by the bearings is given by:

$$
\{\mathrm{p}\}^{(\mathrm{a})}=\left\{\begin{array}{l}
\mathrm{C}_{1} \dot{\mathrm{u}}_{1} \\
\mathrm{C}_{2} \dot{\mathrm{u}}_{2} \\
\mathrm{C}_{3} \dot{\mathrm{u}}_{3}
\end{array}\right\}\left[\delta\left(\mathrm{x}_{1}-\mathrm{l}_{1}\right)+\delta\left(\mathrm{x}_{1}-\mathrm{l}_{2}\right)\right]
$$

Where $\mathrm{C}_{\mathrm{i}}, \mathrm{i}=1,3$ are damping coefficients.

Taking into account the inertial forces and moments introduced by the rotation movement of the spindle, and projecting the movement with respect to a fixed reference system, the mathematical model that establishes the movement equations of the spindle is given by:

$$
\begin{aligned}
& \rho A \ddot{v}_{1}-\mathrm{EAv}_{1,11}=\mathrm{F}^{\mathrm{f}}{ }_{11} \delta\left(\mathrm{x}_{1}-\mathrm{l}_{1}\right)+\mathrm{F}^{\mathrm{f}}{ }_{12} \delta\left(\mathrm{x}_{1}-\mathrm{l}_{2}\right)-\mathrm{c}^{\mathrm{f}} \dot{\mathrm{v}}_{1}\left[\delta\left(\mathrm{x}_{1}-\mathrm{l}_{1}\right)+\delta\left(\mathrm{x}_{1}-\mathrm{l}_{2}\right)\right] \\
& \rho A \ddot{\mathrm{v}}_{3}-\rho \dot{\mathrm{v}}_{3,11}+2 \rho \mathrm{I} \Omega \dot{\mathrm{v}}_{2,11}+\rho \mathrm{I} \Omega^{2} \mathrm{v}_{3,11}+\mathrm{EIv}_{3,1111}=\mathrm{M}^{\mathrm{f}}{ }_{21} \delta\left(\mathrm{x}_{1}-1_{1}\right)+\mathrm{M}^{\mathrm{f}}{ }_{22} \delta\left(\mathrm{x}_{1}-1_{2}\right)+ \\
& +\mathrm{F}^{\mathrm{f}}{ }_{31} \delta\left(\mathrm{x}_{1}-1_{1}\right)+\mathrm{F}^{\mathrm{f}}{ }_{32} \delta\left(\mathrm{x}_{1}-1_{2}\right)-\mathrm{c}^{\mathrm{f}}{ }_{3{ }_{3}} \dot{\mathrm{v}}_{3}\left[\delta\left(\mathrm{x}_{1}-1_{1}\right)+\delta\left(\mathrm{x}_{1}-1_{2}\right)\right] \\
& -\rho \mathrm{A} \ddot{\mathrm{v}}_{2}+\rho \mathrm{I} \ddot{\mathrm{v}}_{2,11}+2 \rho \mathrm{I} \Omega \dot{\mathrm{v}}_{3,11}-\rho \Omega^{2} \mathrm{v}_{2,11}-\mathrm{EIv}_{2,1111}=\mathrm{M}^{\mathrm{f}}{ }_{31} \delta\left(\mathrm{x}_{1}-1_{1}\right)+\mathrm{M}^{\mathrm{f}}{ }_{32} \delta\left(\mathrm{x}_{1}-1_{2}\right)- \\
& -\mathrm{F}^{\mathrm{f}}{ }_{21} \delta\left(\mathrm{x}_{1}-1_{1}\right)-\mathrm{F}^{\mathrm{f}}{ }_{22} \delta\left(\mathrm{x}_{1}-1_{2}\right)+\mathrm{c}^{\mathrm{f}}{ }_{2} \dot{\mathrm{v}}_{2}\left[\delta\left(\mathrm{x}_{1}-1_{1}\right)+\delta\left(\mathrm{x}_{1}-1_{2}\right)\right]
\end{aligned}
$$

Where $\mathrm{F}_{\mathrm{ji}}^{\mathrm{f}}$ and $\mathrm{M}_{\mathrm{ji}}^{\mathrm{f}}-\mathrm{i}, \mathrm{j}=\overline{1,3}$ are the external actions with respect to the fixed reference system.

\section{DETERMINING THE BALANCE CONFIGURATION}

In this case, upon the ensemble spindle-bearings-tool actions a system of external actions that produces a deformation of the spindle, without causing it to vibrate. The movement equations are:

$$
\begin{aligned}
& \operatorname{EAv}_{1,11}=0 \\
& \rho I \Omega^{2} v_{2,11}+\operatorname{EIv}_{2,1111}=0 \\
& \rho I \Omega^{2} v_{3,11}+\operatorname{EIv}_{3,1111}=0
\end{aligned}
$$

After integration, these give solutions of the form:

$$
\begin{aligned}
& \mathrm{v}_{1}=\mathrm{A}_{1} \mathrm{x}_{1}+\mathrm{A}_{2} \\
& \mathrm{v}_{2}=\mathrm{B}_{1} \mathrm{x}_{1}+\mathrm{B}_{2}+\mathrm{B}_{3} \cos C \mathrm{x}_{1}+\mathrm{B}_{4} \sin \mathrm{Cx}_{1} \\
& \mathrm{v}_{3}=\mathrm{D}_{1} \mathrm{x}_{1}+\mathrm{D}_{2}+\mathrm{D}_{3} \cos \mathrm{Cx}_{1}+\mathrm{D}_{4} \sin \mathrm{Cx}_{1}
\end{aligned}
$$

With $\mathrm{C}=\Omega \sqrt{\rho / \mathrm{E}}$. 
The balance conditions will be:

- $\mathrm{x}_{1}=0$

$\operatorname{EAv}_{1,1}^{(0)}(0)=0$

$\operatorname{EIv}_{2,111}^{(0)}(0)-\rho I \Omega^{2} v_{2,1}^{(0)}(0)-\operatorname{EAv}_{1,1}^{(0)}(0) v_{2,1}^{(0)}(0)=0$

$\operatorname{EIv}_{3,111}^{(0)}(0)-\rho I \Omega^{2} v_{3,1}^{(0)}(0)-\operatorname{EAv}_{1,1}^{(0)}(0) v_{3,1}^{(0)}(0)=0$

$\operatorname{EIv}_{2,11}^{(0)}(0)=0$

$\operatorname{EIv}_{3,11}^{(0)}(0)=0$

- $\mathrm{x}_{1}=\mathrm{l}_{1}: \mathrm{x}_{1}=\mathrm{1}_{2}$

$\left[\mathrm{EAv}_{1,1}\right]_{\mathrm{x}_{1}=l_{\mathrm{i}}^{+}}=\mathrm{F}_{\mathrm{ij}}^{\mathrm{f}_{1}=\mathrm{l}_{\mathrm{i}}^{-}}$

$\left[\operatorname{EIv}_{2,111}+\rho \mathrm{I} \Omega^{2} \mathrm{v}_{2,1}-\mathrm{EAv}_{1,1} \mathrm{v}_{2,1}\right]_{\substack{\mathrm{x}_{1}=l_{\mathrm{i}}^{+} \\ \mathrm{x}_{1}=\mathrm{l}_{\mathrm{i}}^{-}}}=-\mathrm{F}_{\mathrm{i}+1, \mathrm{j}}^{\mathrm{f}^{*}}$

$\left[\operatorname{EIv}_{3,111}+\rho \Omega^{2} \mathbf{v}_{3,1}-\mathrm{EAv}_{1,1} \mathrm{v}_{3,1}\right]_{\mathrm{x}_{1}=l_{\mathrm{i}}^{+}}=-\mathrm{F}_{\mathrm{i}+2, \mathrm{j}}^{\mathrm{f}_{1}^{*} \mathrm{l}_{\mathrm{i}}^{-}}$

$\left[\operatorname{EAv}_{3,11}\right]_{\mathrm{x}_{1}=l_{1}^{+}}=-\mathrm{M}_{\mathrm{i}+1, \mathrm{j}}^{\mathrm{f}_{1}=\mathrm{l}_{\mathrm{i}}^{-}}$

$\left[\operatorname{EAv}_{2,11}\right]_{\mathrm{x}_{1}=l_{i}^{+}}=\mathrm{M}_{\mathrm{i}+2, \mathrm{j}}^{\mathrm{x}_{1}=1_{\mathrm{i}}^{-}} \underset{\mathrm{f}}{\mathrm{f}} \quad \mathrm{j}=\overline{1,2}$

$\mathrm{v}_{1}^{\mathrm{i}-1}\left(1_{\mathrm{i}}\right)=\mathrm{v}_{1}^{\mathrm{i}}\left(1_{\mathrm{i}}\right)$

$\mathrm{v}_{2}^{\mathrm{i}-1}\left(1_{\mathrm{i}}\right)=\mathrm{v}_{2}^{\mathrm{i}}\left(1_{\mathrm{i}}\right)$

$\mathrm{v}_{3}^{\mathrm{i}-1}\left(1_{\mathrm{i}}\right)=\mathrm{v}_{3}^{\mathrm{i}}\left(1_{\mathrm{i}}\right) \quad \mathrm{i}=\overline{1,2}$

$\mathrm{v}_{2,1}^{\mathrm{i}-1}\left(1_{\mathrm{i}}\right)=\mathrm{v}_{2,1}^{\mathrm{i}}\left(\mathrm{l}_{\mathrm{i}}\right)$

$\mathrm{v}_{3,1}^{\mathrm{i}-1}\left(1_{\mathrm{i}}\right)=\mathrm{v}_{3,1}^{\mathrm{i}}\left(1_{\mathrm{i}}\right)$

- $\mathrm{x}_{1}=1$

$\operatorname{EAv}_{1,1}^{(2)}(1)=\mathrm{R}_{1}^{\mathrm{f}^{*}}$

$\operatorname{EIv}_{2,111}^{(2)}(1)+\rho I \Omega^{2} v_{2,1}^{(2)}(1)-\operatorname{EAv}_{1,1}^{(2)}(1) v_{2,1}^{(2)}(1)+m_{p} \Omega^{2} v_{2}^{(2)}(1)=-R_{2}^{f^{*}}$

$\operatorname{EIv}_{3,111}^{(2)}(1)+\rho I \Omega^{2} v_{3,1}^{(2)}(1)-\operatorname{EAv}_{1,1}^{(2)}(1) v_{3,1}^{(2)}(1)+m_{p} \Omega^{2} v_{3}^{(2)}(1)=-R_{3}^{f^{*}}$

$\operatorname{EIv}_{3,11}^{(2)}(1)+J_{0} \Omega^{2} v_{3,1}^{(2)}(1)=-M_{2}^{f^{*}}$ 
Determining the Balance Configuration, In Case of The Oscillating Movement of The Main Spindle at CNC Lathe

$\operatorname{EIv}_{2,11}^{(2)}(1)-\mathrm{J}_{0} \Omega^{2} \mathrm{v}_{2,1}^{(2)}(1)=\mathrm{MR}_{3}^{\mathrm{f}^{*}}$

With: $\mathrm{J}_{0}$ - inertial moment of tool and $\mathrm{R}_{\mathrm{j}}^{\mathrm{f}^{*}}$ and $\mathrm{MR}_{\mathrm{j}}^{\mathrm{f}^{*}}, \mathrm{j}=\overline{1,3}$ are external actions in the static case.

\section{CONCLUSIONS}

- Establishment of the balance configuration creates the premises for the stability analysis of the main spindle, in longitudinal and transversal direction at CNC turning.

- Determining the balance configuration is performed using Hamilton's variational principle, the impulse derivative axiom and the kinetic moment derivative axiom.

- The balance configuration is achieved by ensuring that the systems of forces acting upon the main shaft - cutting tool -support bearings ensemble cause its deformation without producing vibrations.

- In case of CNC milling the vibration, analysis is very significant with respect to the precision level and the surface quality. The type of material and its hardness influence the vibration level [4]. At the same time an important factor is the influence of the processing tool support and its geometric configuration [5], [6].

\section{REFERENCES}

[1] Popescu, D., Theoretical and Experimental Contributions Regarding Improvement of The Processing Precision at Internal Grinding Machines, 1999, PhD Thesis, University of Bucharest, p.95-97.

[2] Shin, Y., C., Bearing Nonlinearity and Stability Analysis in High-Speed Machining, 1992, Trans. ASME J. Engr. For Industry, vol.114, p.23-30.

[3] Wandle, F., P., Dynamic and Static Characteristics of a Wide Spread Range Machine Tool Spindle, 1983, Precision Engineering, vol.5, nr.3, p.175-183.

[4] Abdulhani, F., A Lswede, J., Study of Vibration for CNC Machine at Difference Feed, International Journal of Advancements in Research \& Technology, Volume 3, Issue 11, November -2014 21, ISSN 2278-7763.

[5] Beards, C.F., Engineering Vibration analysis with Application to control Systems, (C) 1995.

[6] Douglas, T., Structural dynamics and vibration in practice, 2008, C), pg1. 